\title{
Monitoring of high-density lipoprotein cholesterol level is predictive of EGFR mutation and efficacy of EGFR-TKI in patients with advanced lung adenocarcinoma
}

\author{
This article was published in the following Dove Press journal: \\ OncoTargets and Therapy \\ 22 January 2016 \\ Number of times this article has been viewed
}

\author{
Yang $L v^{1,2}$ \\ Li-Yun Miao ${ }^{2}$ \\ Qiu-Fang Chen' \\ Yan $\mathrm{Li}^{2}$ \\ Zhi-Xiang Shi' \\ Xuan-Sheng Ding' \\ 'Department of Clinical Pharmacy, \\ China Pharmaceutical University, \\ Nanjing, Jiangsu, People's Republic \\ of China; ${ }^{2}$ Division of Respiratory \\ Medicine, Department of Respiration, \\ The Affiliated Drum Tower Hospital \\ of Nanjing University Medical College, \\ Nanjing University Medical School, \\ Nanjing, Jiangsu, People's Republic of \\ China
}

\begin{abstract}
High-density lipoprotein cholesterol (HDL-C) has an inverse association with the incidence of lung cancer. However, whether it can be used as a predictive factor in advanced lung adenocarcinoma patients treated with epidermal growth factor receptor (EGFR) tyrosine kinase inhibitors (TKI) still remains undefined. This research aimed at studying the relationship of serum HDL-C baseline level and HDL-C kinetics to EGFR mutation, the efficacy of EGFRTKI, and the predictive value of PFS. The presence of mutation rate in the 192 patients with lung adenocarcinoma was compared within stratified groups. Levels of baseline HDL-C and kinetics of HDL-C were analyzed retrospectively in patients treated with EGFR-TKI harboring EGFR mutation. Univariate and multivariate analyses were performed to investigate the prognostic value of HDL-C. EGFR mutation rate of HDL-C high-level group was significantly higher than that of low-level group (59.0\% vs 35.6\%, $P=0.001)$. Multivariate logistic analysis showed that high-level HDL-C was an independent predictive factor for EGFR gene mutation $(P=0.005$; odds ratio $=0.417 ; 95 \%$ confidence interval $[\mathrm{CI}], 0.227-0.768)$. Patients with a low level of HDL-C before therapy showed a progression of disease in most cases $(P<0.001)$. According to HDL-C kinetics, patients who received EGFR-TKI treatment harboring EGFR mutation were divided into four groups. Univariate analysis showed that patients in nondecreased group had longer progression-free survival $(P<0.001$; hazard ratio $=0.003 ; 95 \% \mathrm{CI}, 0.001-0.018)$. Multivariate Cox proportional hazards model analyses showed the same result $(P<0.001$; hazard ratio $=0.003 ; 95 \% \mathrm{CI}, 0.001-0.018$ ). Current results suggest that HDL-C seems to be a good independent predictive biomarker for advanced lung adenocarcinoma patients treated with the first-line EGFR-TKI. Roles of this biomarker include indicating EGFR mutation, assessing the efficacy of EGFR-TKI, and predicting the progression-free survival.
\end{abstract}

Keywords: lung adenocarcinoma, high-density lipoprotein cholesterol, EGFR mutation, EGFR-TKI, PFS

\section{Introduction}

Lung cancer has a high mortality. Lung adenocarcinoma, a common form of lung cancer, has an average 5-year survival rate of $15 \% .{ }^{1}$ Traditional therapies for nonsmall-cell lung cancer include surgery, radiotherapy, and chemotherapy. ${ }^{2,3}$ In recent years, molecular targeted therapy versus specific targeted therapy, which has fewer side effects and longer progression-free survival (PFS) and overall survival (OS), has become a research hotspot., ${ }^{4,5}$

Patients with lung adenocarcinoma frequently overexpress receptors of the erbB family, including the epidermal growth factor receptor (EGFR) encoded by
Correspondence: Xuan-Sheng Ding Department of Clinical Pharmacy, China Pharmaceutical University, 24 Tong Jia Xiang, Nanjing 210009, Jiangsu,

People's Republic of China

Tel +862586185353

Email dingxs0162@sina.com 
erbB-1. ${ }^{6,7}$ EGFR is a $170 \mathrm{kD}$ receptor tyrosine kinase (TK) that dimerizes and phosphorylates several tyrosine residues after binding of several specific ligands. ${ }^{7}$ It has been reported that activating mutation of EGFR is present in a subset of pulmonary adenocarcinoma and that tumors with EGFR mutations are highly sensitive to EGFR-TKI. ${ }^{8,9}$ EGFR mutation tests are complex and require tumor tissue; therefore, simple methods to identify responders prior to EGFR-TKI treatment are urgently needed.

High-density lipoprotein (HDL) may work as a supplier of cholesterol to cancer cells by removing excess cholesterol from peripheral tissues. ${ }^{10}$ It is well-known that low high-density lipoprotein cholesterol (HDL-C) is a strong independent predictor of coronary vascular diseases and a feature of inflammatory disorders. ${ }^{11}$ Recently, many studies have demonstrated that low HDL-C has a significant inverse association with baseline HDL-C levels and the risk of developing cancer, ${ }^{12-14}$ largely attributed to cancers of the lung, prostate, liver, and hematopoietic system, persisted after exclusion of cases diagnosed during the first 12 years of follow-up. In leukemia, plasma lipids can also be considered as early and reliable markers of effectiveness of chemotherapy. ${ }^{15}$ Pleiotropic properties of the HDL-C particle, including its antioxidative function, modulation of cytokine production, blockage of apoptosis, and stimulation of cell proliferation and migration, are more likely to play a role in the development of cancer. ${ }^{16}$

It is still unknown whether HDL-C could be a predictive biomarker for EGFR mutation and the efficacy of EGFRTKI. This study aimed at contributing to the knowledge of the correlation of HDL-C baseline level with kinetics and EGFR mutation, the efficacy of EGFR-TKI, and the predictive value of PFS.

\section{Patients and methods}

\section{Patients}

A total of 192 lung adenocarcinoma patients treated at Division of Respiratory Medicine, the Affiliated Drum Tower Hospital, Nanjing University Medical School, from May 2010 to October 2015 were enrolled in this study. All patients met the following eligible criteria: 1) all patients with a pathological diagnosis of lung adenocarcinoma, 2) all patients who are required to have proven stage IIIB-IV with an Eastern Cooperative Oncology Group performance status (ECOG PS) of 0-2 and to have enough tumor tissue for EGFR testing, 3) all patients in a clear EGFR mutation status, 4) none had received therapy before serum collection, and 5) patients with complete follow-up data. Exclusion criteria for patients are
1) having concomitant diseases associated with increasing serum lipid levels (ie, diabetes, hyperlipidemia, or metabolic syndrome) and 2) taking hormone replacement therapy or any drugs known to affect lipid metabolism. Clinical characteristics recorded included sex, age, stage, smoking history, performance status, and HDL-C.

EGFR mutation detection was performed in all patients. A total of 93 patients had EGFR mutation and received EGFR-TKIs as first-line treatment, with 70 patients treated with gefitinib (Iressa, $250 \mathrm{mg}$ per day, AstraZeneca, London, England), 15 patients treated with erlotinib (Tarceva, $250 \mathrm{mg}$ per day, Roche, Basel, Switzerland), and 8 with icontinib (Conmana, 250 mg per day, Beta Pharma, Zhejiang, People's Republic of China). All 93 patients were first checked to ensure efficacy of EGFR-TKI therapy about 20 days after therapy. Of these 93 patients, HDL-C kinetics were monitored in 75 patients until disease progression. Serum HDL-C levels were measured at baseline and thereafter at the start of each check cycle ( 2 months a cycle).

\section{Patients follow-up}

Patients were regularly followed up after receiving EGFRTKIs until disease progression. They were scheduled to visit the hospital 20 days after the start of receiving EGFR-TKIs, and every 2 months thereafter. The time of the last follow-up was October 10, 2015. Serum HDL-C level was measured, and chest $\mathrm{CT}$ was performed during each visit.

\section{Study design}

Prior to the use of these patients' data, informed written consent was obtained and the study was approved by the Research Ethics Committee of Affiliated Drum Tower Hospital. HDL-C levels were measured at baseline for all the patients. HDL-C was measured at the start of each check cycle until disease progression, in a cycle of 2 months. Serum measurement was performed as described previously. ${ }^{17}$ There were no clearly defined cutoff points for HDL-C in relation to cancer outcomes. Thus, the receiver operating characteristic (ROC) curve analysis was subjected to the selection of cutoff points. The cutoff point of HDL-C was $0.945 \mathrm{mmol} / \mathrm{L}$ with the highest value of "sensitivity + specificity" in the ROC analysis using EGFR mutation as an end point.

\section{Evaluation methods}

The primary end point was PFS. PFS was defined as the time from the date of receiving EGFR-TKI to disease progression or death. Based on the response evaluation criteria in solid tumors (RECIST) 1.0 guidelines, the responses to treatment were 
classified as complete response (CR), partial response (PR), stable disease (SD), and progression of disease (PD). CR and $\mathrm{PR}$ were defined as the overall response rate (ORR), while CR, $\mathrm{PR}$, and SD were defined as the disease control rate (DCR).

\section{Statistical analysis}

The statistical analysis was performed using Statistical Package for Social Science version 19.0 software (SPSS Inc., Chicago, IL, USA). Rates were compared using the $\chi^{2}$-test. Fisher's exact test was used to analyze categorical variables. Multivariate logistic analysis was used to identify the independent variables that were correlated with EGFR mutation. ROC curves were created to evaluate the cutoff point of HDL-C levels in predicting the mutation of EGFR. The survival curves were plotted by the Kaplan-Meier method and compared using the log rank test. The significance of independent variables for PFS was analyzed using the Cox proportional hazards model (univariate and multivariate analyses). All tests were two-tailed, and a $P$ less than 0.05 was considered to be statistically significant.

\section{Results}

\section{High-density lipoprotein cholesterol kinetics}

The cutoff point of HDL-C was $0.945 \mathrm{mmol} / \mathrm{L}$, with the highest value of "sensitivity + specificity" in the ROC analysis using EGFR mutation as an end point (Figure 1).

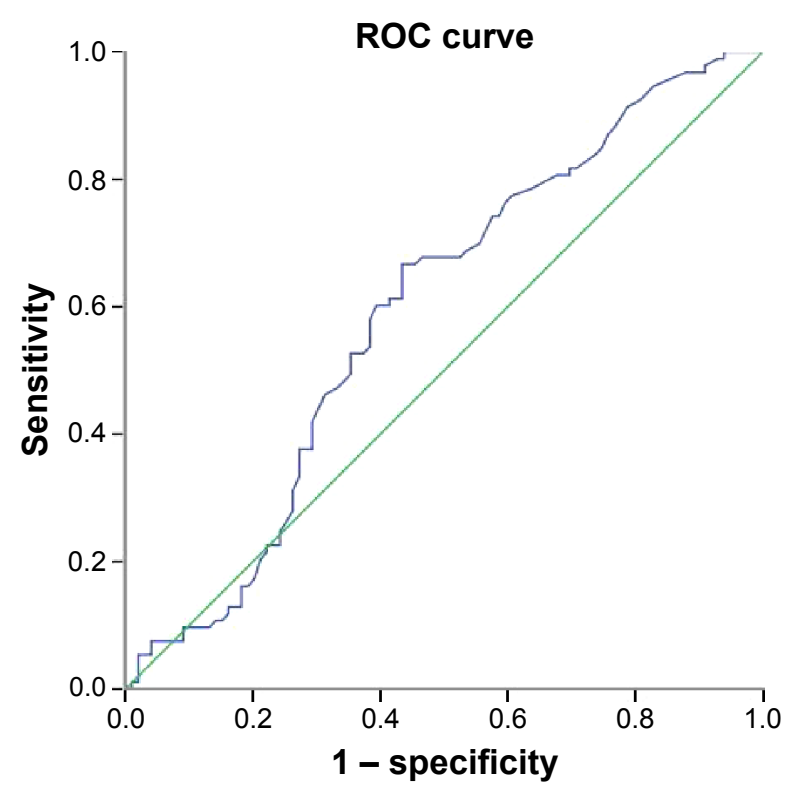

Figure I ROC curves for different HDL-C baseline levels in relation to the EGFR mutation, with the highest value of "sensitivity + specificity", the cutoff point of HDL-C was $0.945 \mathrm{mmol} / \mathrm{L}$.

Abbreviations: EGFR, epidermal growth factor receptor; HDL-C, high-density lipoprotein cholesterol; ROC, receiver operating characteristic.
According to HDL-C kinetics, the patients were divided into four groups: 1) patients whose HDL-C $>0.945 \mathrm{mmol} / \mathrm{L}$ and never decreased during treatment; 2) patients whose HDL-C $>0.945 \mathrm{mmol} / \mathrm{L}$ and decreased at least one time during treatment; 3) patients whose HDL-C $\leq 0.945 \mathrm{mmol} / \mathrm{L}$ and normalized at least one time during treatment; 4) patients whose HDL-C $\leq 0.945 \mathrm{mmol} / \mathrm{L}$ and never normalized during treatment. The patients were assigned to nondecreased, decreased, normalized, and nonnormalized HDL-C groups, respectively.

\section{Patients' characteristics}

Correlation of patients' demographic and baseline characteristics with EGFR mutation are described in Table 1. The median age of 192 patients was 61.8 years (range: $33-89$ years). The majority of patients were female (53.7\%), nonsmokers (78.1\%), with PS 0-1 (58.3\%), and stage IV (77.6\%). EGFR mutation was documented in $48.4 \%$ of cases $(\mathrm{n}=93)$, of which $46.2 \%(\mathrm{n}=43)$ harbored exon 19 deletion, $48.4 \%(n=45)$ exon 21 L858R mutation, and 5.4\% $(n=6)$ both exon 19 and exon 21 mutation (Table 2). All patients (93 cases) with EGFR mutation received EGFR-TKI as first-line treatment: 70 patients $(75.3 \%)$ received gefitinib, $15(16.1 \%)$ erlotinib, and $8(8.6 \%)$ icontinib. Patients without EGFR mutation (99 cases) received platinum-based chemotherapy as first-line treatment.

\section{Correlation of HDL-C baseline level with EGFR mutation}

The correlation between EGFR mutation and clinical characteristics was analyzed, with the finding that HDL-C baseline level, sex, and smoking history were correlative factors (Table 1). EGFR mutation rate in HDL-C high-level group was significantly higher than low-level group $(59.0 \%$ vs $35.6 \%, P=0.001)$. Taking all these correlative factors into multivariate logistic analysis, it was found that high level of HDL-C was independently associated with EGFR gene mutation $(P=0.005$; odds ratio $[\mathrm{OR}]=0.417 ; 95 \%$ confidence interval [CI], 0.227-0.768) (Table 2).

\section{Correlation between HDL-C level and efficacy of EGFR-TKIs}

Approximately 93 patients received EGFR-TKI as first-line treatment. Assessed after the first course of TKI therapy, the total ORR was $61.3 \%$, while DCR was $91.4 \%$. Baseline serum HDL-C level behaved differently in high- and low-level groups. A higher proportion of progression was observed in low-level HDL-C, and HDL-C was the only 
Table I The relationship between the clinical characteristic and EGFR mutation

\begin{tabular}{|c|c|c|c|c|}
\hline Characteristics & Number of patients & Number of mutations $(+)$ & Rate (\%) & $P$-value \\
\hline \multicolumn{5}{|l|}{ Sex } \\
\hline Male & 89 & 36 & 40.4 & 0.044 \\
\hline Female & 103 & 57 & 55.3 & \\
\hline \multicolumn{5}{|l|}{ Age, years } \\
\hline$\leq 61.8$ & 93 & 50 & 53.8 & 0.193 \\
\hline$>61.8$ & 99 & 43 & 43.4 & \\
\hline \multicolumn{5}{|l|}{ Smoking history } \\
\hline Yes & 42 & 13 & 31.0 & 0.014 \\
\hline No & 150 & 80 & 53.3 & \\
\hline \multicolumn{5}{|l|}{ Performance status } \\
\hline $0-1$ & 112 & 61 & 54.5 & 0.057 \\
\hline 2 & 80 & 32 & 40.0 & \\
\hline \multicolumn{5}{|l|}{ Staging } \\
\hline IIIB & 43 & 22 & 51.2 & 0.731 \\
\hline IV & 149 & 71 & 47.7 & \\
\hline \multicolumn{5}{|l|}{ HDL-C (mmol/L) } \\
\hline$\leq 0.945$ & 87 & 31 & 35.6 & 0.001 \\
\hline$>0.945$ & 105 & 62 & 59.0 & \\
\hline
\end{tabular}

Abbreviations: EGFR, epidermal growth factor receptor; HDL-C, high-density lipoprotein cholesterol.

influencing factor among all the clinical characteristics (25.8\%, $P<0.001$ ) (Table 3). Therefore, baseline HDL-C level seems to have the potential to predict clinical response to EGFR-TKIs therapy.

\section{HDL-C kinetics and progression-free survival}

According to the follow-up data, 75 out of 93 patients continued EGFR-TKI therapy until disease progression. By the variation types of HDL-C during the treatment, the patients were divided into four groups: nondecreased group, normalized group, decreased group, and nonnormalized group. The baseline HDL-C levels of these four groups were nondecreased group whose HDL-C levels did not decrease during the treatment $(>0.945 \mathrm{mmol} / \mathrm{L}, \mathrm{n}=29)$, decreased group whose HDL-C levels decreased at least one time $(>0.945 \mathrm{mmol} / \mathrm{L}, \mathrm{n}=19)$, normalized group whose HDL-C levels normalized at least once $(\leq 0.945 \mathrm{mmol} / \mathrm{L}$, $\mathrm{n}=16$ ), and nonnormalized group whose HDL-C levels remained decreased $(\leq 0.945 \mathrm{mmol} / \mathrm{L}, \mathrm{n}=11)$. Median PFS lengths were 12.8 months in the nondecreased HDL-C group, 7.7 months in decreased HDL-C group, 6.2 months in the normalized HDL-C group, and 1.9 months in the nonnormalized HDL-C group. There was a significant difference in PFS rates between the four groups $(P<0.001$; Figure 2). Univariate analysis of relevance between clinical characteristics and PFS showed that males with lower HDL-C baseline level (Figure 3), HDL-C kinetics status (normalized group, decreased group, nonnormalized group), had a shorter PFS (Table 4). Multivariate Cox proportional hazards model analysis of various factors affecting PFS showed lower baseline HDL-C had shorter PFS $(P<0.001$; hazard ratio $[\mathrm{HR}]=0.126$; 95\% CI, 0.064-0.247), while the nondecreased group in HDL-C kinetics status had longer PFS $(P<0.001 ; \mathrm{HR}=0.003 ; 95 \%$ CI, 0.001-0.018) (Table 5).

Table 2 Multivariate logistic analysis of factors associated with EGFR mutation

\begin{tabular}{lllll}
\hline Variables & Category & Odds ratio & 95\% confidence interval & $P$-value \\
\hline Sex & Male & & & $0.456-1.739$ \\
Semale & Yes & 0.890 & 0.734 \\
No & $0-1$ & 0.454 & $0.199-1.038$ & 0.061 \\
Performance status & 2 & & $0.832-2.817$ & 0.171 \\
HDL-C & $\leq 0.945$ & 1.531 & & $0.227-0.768$ \\
& $>0.945$ & 0.417 & 005 \\
\hline
\end{tabular}

Abbreviations: EGFR, epidermal growth factor receptor; HDL-C, high-density lipoprotein cholesterol. 
Table 3 Relevance between the clinical characteristics and efficacy of EGFR-TKI

\begin{tabular}{|c|c|c|c|c|c|}
\hline Characteristics & Number & PR & SD & PD & $P$-value \\
\hline \multicolumn{6}{|l|}{ Sex } \\
\hline Male & 36 & 17 & 14 & 5 & \multirow[t]{2}{*}{$0.086^{a}$} \\
\hline Female & 57 & 40 & 14 & 3 & \\
\hline \multicolumn{6}{|l|}{ Age, years } \\
\hline$\leq 61.8$ & 50 & 33 & 14 & 3 & \multirow[t]{2}{*}{$0.53 \mathrm{I}^{\mathrm{a}}$} \\
\hline$>61.8$ & 43 & 24 & 14 & 5 & \\
\hline \multicolumn{6}{|l|}{ Smoking history } \\
\hline Yes & 13 & 5 & 6 & 2 & \multirow[t]{2}{*}{$0.234^{a}$} \\
\hline No & 80 & 52 & 22 & 6 & \\
\hline \multicolumn{6}{|l|}{ Performance status } \\
\hline $0-1$ & 61 & 37 & 19 & 5 & \multirow[t]{2}{*}{$0.946^{a}$} \\
\hline 2 & 32 & 20 & 9 & 3 & \\
\hline \multicolumn{6}{|l|}{ Staging } \\
\hline IIIB & 22 & 13 & 8 & 1 & \multirow[t]{2}{*}{$0.568^{\mathrm{a}}$} \\
\hline IV & 71 & 44 & 20 & 7 & \\
\hline \multicolumn{6}{|l|}{$\mathrm{HDL}-\mathrm{C}(\mathrm{mmol} / \mathrm{L})$} \\
\hline$\leq 0.945$ & 31 & 11 & 12 & 8 & \multirow[t]{2}{*}{$<0.001^{2}$} \\
\hline$>0.945$ & 62 & 46 & 16 & 0 & \\
\hline \multicolumn{6}{|l|}{ EGFR-TKI } \\
\hline Gefitinib & 70 & 45 & 21 & 4 & \multirow[t]{3}{*}{$0.17 I^{b}$} \\
\hline Erlotinib & 15 & 9 & 3 & 3 & \\
\hline Icotinib & 8 & 3 & 4 & I & \\
\hline \multicolumn{6}{|l|}{ Mutation type } \\
\hline Exon 19 & 43 & 24 & 13 & 6 & \multirow[t]{3}{*}{$0.532^{\mathrm{b}}$} \\
\hline Exon 21 & 45 & 30 & 13 & 2 & \\
\hline Exon $19+21$ & 5 & 3 & 2 & 0 & \\
\hline
\end{tabular}

Notes: aLikelihood ratio; 'Fisher's exact test.

Abbreviations: EGFR-TKI, epidermal growth factor receptor-tyrosine kinase inhibitor; HDL-C, high-density lipoprotein cholesterol; PR, partial response; SD, stable disease; PD, progressive disease.

\section{Discussion}

Decreased circulating HDL-C level has been associated with decreased cancer survival in a previous study. ${ }^{15}$ Our former study has demonstrated that ApoA-1, a major polypeptide of human plasma HDL, is a useful prognostic factor for survival in advanced NSCLC patients treated with chemotherapy. ${ }^{18}$ To the best of our knowledge, this is the first study to investigate the association of HDL-C with EGFR mutation status and efficacy of EGFR-TKI. Using stratification and regression model, our results demonstrated that HDL-C was a useful predictive factor for EGFR mutation, efficacy of EGFR-TKI, and a prognostic factor for PFS in advanced lung adenocarcinoma patients treated with EGFR-TKI harboring EGFR mutation.

It has been reported that EGFR mutations mainly occur in exon 19 and 21, and these mutations have an important relationship with tumor cell sensitivity to EGFR-TKI therapy. ${ }^{19-22}$ Studies have shown that EGFR mutation rate has regional differences, as it is roughly $10 \%$ in Western countries but $50 \%$ in Asian countries, nonsmokers, women,

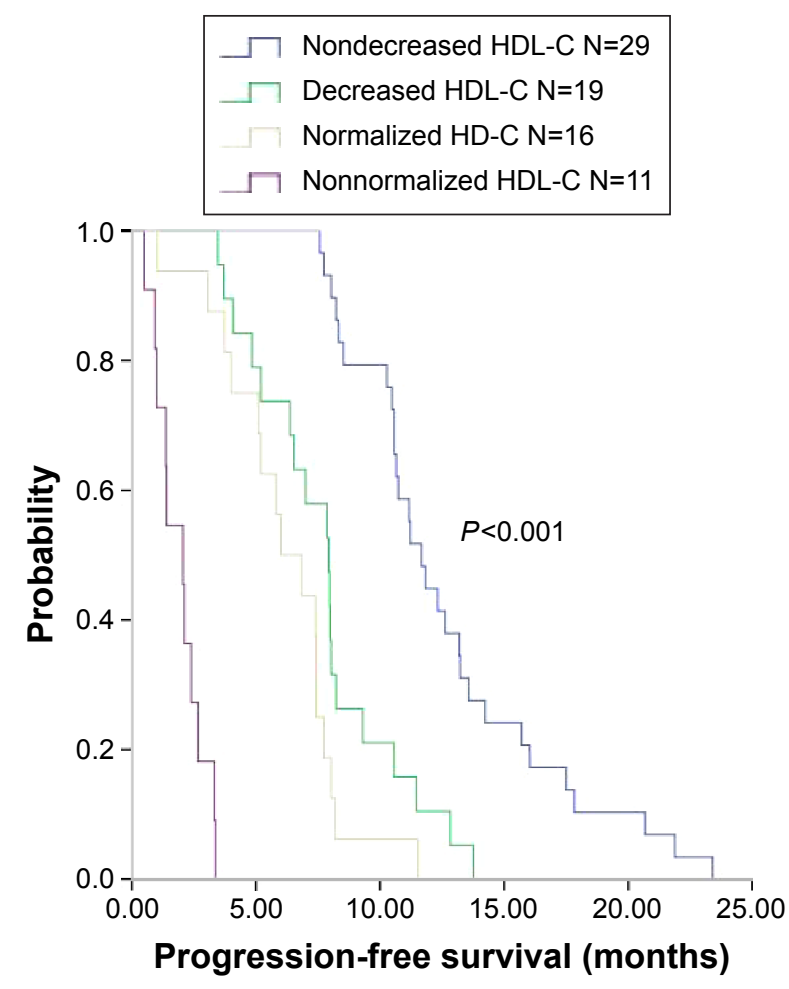

Figure 2 PFS for EGFR-TKI treatment.

Notes: The PFS curves of EGFR-TKI-treated patients with different HDL-C kinetics. Patients whose HDL-C $>0.945 \mathrm{mmol} / \mathrm{L}$ and never decreased during treatment of EGFR-TKI have an increasing trend on the subsequent time points.

Abbreviations: PFS, progression-free survival; EGFR-TKI, epidermal growth factor receptor-tyrosine kinase inhibitor; HDL-C, high-density lipoprotein cholesterol.

and patients with adenocarcinoma. ${ }^{20}$ Similar to previous reports, the results of our study revealed that nonsmokers and women have a higher EGFR mutation rate. Additionally, it was found that EGFR mutation was closely related to the baseline HDL-C level, and a higher mutation rate occurred in the high-level group.

HDL-C is a part of cholesterol. HDL particles play an important role in removing the excess cholesterol from peripheral tissues to initiate reverse transport of cholesterol to the liver. ${ }^{23}$ Cholesterol is also known to accumulate in special regions of the membrane, combined with sphingolipids creating small compartmentalized and highly stable microdomains known as lipid rafts. Lipid rafts are referred to as the sites of signaling platforms that convey stimuli of the extracellular milieu to the intracellular systems in normal and cancer cells. ${ }^{24}$ EGFR is associated with lipid rafts, and its signaling events are dependent on the cholesterol content of lipid rafts. The disruption of the lipid rafts via depletion of circulating cholesterol levels interferes with the receptor activation and subsequent inhibition of cell growth and development. ${ }^{25-27}$ Another research also supported the theory. ${ }^{28}$ When lipid rafts were depleted of cholesterol using lovastatin, all four 


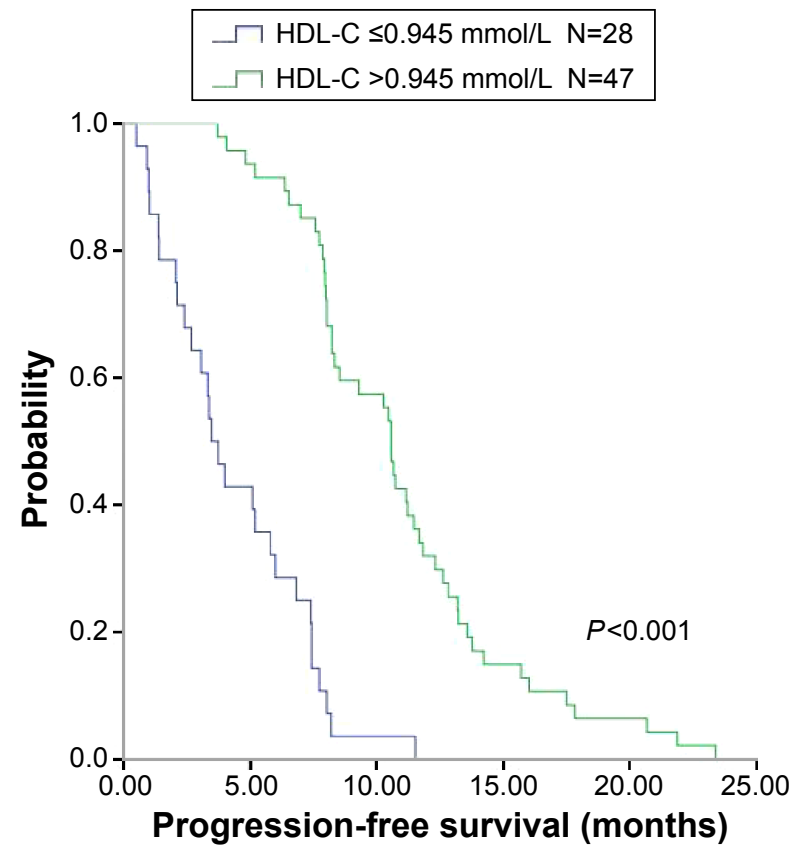

Figure 3 PFS for EGFR-TKI treatment.

Notes: The PFS curves of EGFR-TKI-treated patients with different baseline HDL-C levels. Patients whose HDL-C $>0.945 \mathrm{mmol} / \mathrm{L}$ before treatment of EGFR-TKI have a longer PFS $(P<0.001)$.

Abbreviations: PFS, progression-free survival; EGFR-TKI, epidermal growth factor receptor-tyrosine kinase inhibitor; HDL-C, high-density lipoprotein cholesterol.

EGFR TKI-resistance cell lines were sensitized. The effects of cholesterol biosynthesis inhibitors and EGFR-TKIS were synergistic. All of the findings mentioned above revealed that EGFR mutation status and HDL-C expression level had important effects on the lipid raft.

Our study has also demonstrated that HDL-C can be a predictive biomarker of the efficacy of EGFR-TKI and that it has a relationship with PFS. Previous studies showed that HDL-C
Table 4 Univariate analysis for progression-free survival in EGFRTKI-treated patients

\begin{tabular}{|c|c|c|c|c|}
\hline Characteristics & Number & HR & $95 \% \mathrm{Cl}$ & $P$-value \\
\hline \multicolumn{5}{|l|}{ Age, years } \\
\hline$\leq 61.8$ vs $>61.8$ & 4 I vs 34 & 1.344 & $0.847-2.130$ & 0.209 \\
\hline \multicolumn{5}{|l|}{ Sex } \\
\hline Male vs female & 27 vs 48 & 0.566 & $0.344-0.932$ & 0.025 \\
\hline \multicolumn{5}{|l|}{ Smoking history } \\
\hline Yes vs no & 12 vs 63 & 0.689 & $0.366-1.296$ & 0.248 \\
\hline \multicolumn{5}{|l|}{ Performance status } \\
\hline $0-I$ vs 2 & 48 vs 27 & 1.544 & $0.940-2.538$ & 0.087 \\
\hline \multicolumn{5}{|l|}{ Staging } \\
\hline IIIB vs IV & 20 vs 55 & 0.799 & $0.472-1.353$ & 0.404 \\
\hline \multicolumn{5}{|l|}{ HDL-C (mmol/L) } \\
\hline$\leq 0.945$ vs $>0.945$ & 28 vs 47 & 0.151 & $0.086-0.266$ & $<0.001$ \\
\hline \multicolumn{5}{|l|}{ EGFR-TKI } \\
\hline Gefitinib & 56 & & & \\
\hline Erlotinib & 12 & 1.124 & $0.596-2.118$ & 0.718 \\
\hline Icotinib & 7 & 1.777 & $0.798-3.959$ & 0.159 \\
\hline \multicolumn{5}{|l|}{ Mutation type } \\
\hline Exon 19 & 33 & & & \\
\hline Exon 21 & 37 & 0.614 & $0.380-0.992$ & 0.046 \\
\hline Exon $19+21$ & 5 & 0.928 & $0.360-2.392$ & 0.928 \\
\hline \multicolumn{5}{|l|}{ HDL-C kinetics } \\
\hline Nondecreased & 29 & 0.003 & $0.00 \mathrm{I}-0.018$ & $<0.001$ \\
\hline Normalized & 19 & 0.012 & $0.002-0.062$ & $<0.001$ \\
\hline Decreased & 16 & 0.026 & $0.005-0.130$ & $<0.001$ \\
\hline Nonnormalized & 11 & & & \\
\hline
\end{tabular}

Abbreviations: EGFR-TKI, epidermal growth factor receptor-tyrosine kinase inhibitor; $\mathrm{HR}$, hazard ratio; $\mathrm{Cl}$, confidence interval; HDL-C, high-density lipoprotein cholesterol.

levels decreased with cancer progression, while returning to normal after successful chemotherapy. ${ }^{29-31}$ The metabolism of HDL during tumor growth leading to the distribution of HDL subfractions changed with a sharp decrease in $\mathrm{HDL}_{3}$ and a consequent increase of normal $\mathrm{HDL}_{2} / \mathrm{HDL}_{3}$ ratio in

Table 5 Multivariate Cox hazards analysis for progression-free survival in EGFR-TKI-treated patients

\begin{tabular}{|c|c|c|c|c|c|c|c|}
\hline \multirow[t]{2}{*}{ Characteristics } & \multirow[t]{2}{*}{ Number } & \multicolumn{3}{|c|}{ Model I } & \multicolumn{3}{|c|}{ Model 2} \\
\hline & & HR & $95 \% \mathrm{Cl}$ & $P$-value & HR & $95 \% \mathrm{Cl}$ & $P$-value \\
\hline \multicolumn{8}{|l|}{ Sex } \\
\hline Male vs female & 27 vs 48 & 0.865 & $0.462-1.617$ & 0.649 & 1.174 & $0.615-2.242$ & 0.626 \\
\hline \multicolumn{8}{|l|}{ Smoking history } \\
\hline Yes vs no & 12 vs 63 & 2.039 & $0.899-4.625$ & 0.088 & 1.243 & $0.522-2.959$ & 0.623 \\
\hline \multicolumn{8}{|l|}{ Performance status } \\
\hline $0-1$ vs 2 & 48 vs 27 & 1.456 & $0.866-2.446$ & 0.156 & 1.419 & $0.827-2.433$ & 0.204 \\
\hline \multicolumn{8}{|l|}{ HDL-C (mmol/L) } \\
\hline$\leq 0.945$ vs $>0.945$ & 28 vs 47 & 0.126 & $0.064-0.247$ & $<0.001$ & & & \\
\hline \multicolumn{8}{|l|}{ HDL-C kinetics } \\
\hline Nondecreased & 29 & & & & 0.003 & $0.001-0.018$ & $<0.001$ \\
\hline Normalized & 19 & & & & 0.13 & $0.002-0.068$ & $<0.001$ \\
\hline Decreased & 16 & & & & 0.029 & $0.006-0.152$ & $<0.001$ \\
\hline Nonnormalized & 11 & & & & & & \\
\hline
\end{tabular}

Notes: The multivariate Cox hazards analysis for model I includes sex, smoking history, performance status and baseline HDL-C, while the model 2 includes sex, smoking history, performance status and HDL-C kinetics. The baseline HDL-C and HDL-C kinetics are the main difference between model I and model 2.

Abbreviations: EGFR-TKI, epidermal growth factor receptor-tyrosine kinase inhibitor; HR, hazard ratio; Cl, confidence interval; HDL-C, high-density lipoprotein cholesterol. 
neoplastic patients. ${ }^{32}$ Similar to previous research, patients with low-level HDL-C before therapy in our research had a poor response to EGFR-TKI, and a substantial decrease in HDL-C during treatment had a shorter PFS. Patients receiving EGFR-TKI treatment, whose HDL-C levels were lower before therapy and never returned to normal, had the shortest PFS (1.9 months). Patients who had a higher HDL-C, which never decreased during the treatment, had the longest PFS (12.8 months). Such a phenomenon may be due to the antiinflammatory and antioxidant properties ${ }^{33-35}$ of HDL-C.

According to the NCCN Guideline 2015, all the patients were required to be screened to detect EGFR mutation. Only those with positive EGFR mutation were recommended EGFR-TKI as first-line treatment. However, the tumor tissue for EGFR testing is often not sufficient, and patients harboring EGFR-sensitive mutations benefit in different degrees from EGFR-TKI treatment. Since HDL-C can work as a predictive biomarker, clinicians can predict the efficacy and PFS through monitoring HDL-C, which may provide certain reference. It may be more convenient for them to develop a rational treatment plan as early as possible to benefit different patients.

Taken together, the current results indicate that HDL-C can be used as a potential biomarker for advanced lung adenocarcinoma patients treated with first-line EGFR-TKI. The roles of this biomarker include indicating EGFR mutation, assessing the efficacy of EGFR-TKI, and predicting the PFS. Dynamitic HDL-C measurements are useful to help estimate the true status of tumor. Yet, large-scale studies are needed to confirm our results.

\section{Disclosure}

The authors report no conflicts of interest in this work.

\section{References}

1. Siegel RL, Miller KD, Jemal A. Cancer statistic, 2015. CA Cancer J Clin. 2015;65(1):5-29.

2. Yang ZM, Ding XP, Pen L, Mei L, Liu T. Analysis of CEA expression and EGFR mutation status in non-small cell lung cancers. Asian Pac $J$ Cancer Prev. 2014;15(8):3451-3455.

3. Soltanian S, Matin MM. Cancer stem cells and cancer therapy. Tumour Biol. 2011;32(3):425-440.

4. Granberg D, Wilander E, Oberg K. Expression of tyrosine kinase receptors in lung carcinoids. Tumour Biol. 2006;27(3):153-157.

5. De Mello RA, Pires FS, Marques DS, et al. EGFR exon mutation distribution and outcome in non-small-cell lung cancer: a Portuguese retrospective study. Tumour Biol. 2012;33(6):2061-2068.

6. Arteaga CL. Overview of epidermal growth factor receptor biology and its role as a therapeutic target in human neoplasia. Semin Oncol. 2002;29 (5 Suppl 14):3-9.

7. Bunn PA Jr, Franklin W. Epidermal growth factor receptor expression, signal pathway, and inhibitors in non-small cell lung cancer. Semin Oncol. 2002;29(5 Suppl 14):38-44.
8. Paez JG, Jänne PA, Lee JC, et al. EGFR mutations in lung cancer: correlation with clinical response to gefitinib therapy. Science. 2004; 304(5676):1497-1500.

9. Lynch TJ, Bell DW, Sordella R, et al. Activating mutations in the epidermal growth factor receptor underlying responsiveness of non-small-cell lung cancer to gefitinib. $N$ Engl J Med. 2004;350(21):2129-2139.

10. Cruz PM, Mo H, McConathy WJ, Sabnis N, Lacko AG. The role of cholesterol metabolism and cholesterol transport in carcinogenesis: a review of scientific findings, relevant to future cancer therapeutics. Front Pharmacol. 2013;4:119.

11. Yoshikawa T, Noguchi Y, Doi C, Makino T, Nomura K. Insulin resistance in patients with cancer: relationships with tumor site, tumor stage, bodyweight loss, acutephase response, and energy expenditure. Nutrition. 2001;17(7-8):590-593.

12. Llaverias G, Danilo C, Mercier I, et al. Role of cholesterol in the development and progression of breast cancer. Am J Pathol. 2011;178(1): 402-412.

13. Ahn J, Lim U, Weinstein SJ, et al. Prediagnostic total and high-density lipoprotein cholesterol and risk of cancer. Cancer Epidemiol Biomarkers Prev. 2009;18(11):2814-2821.

14. Jafri H, Alsheikh-Ali AA, Karas RH. Baseline and on-treatment highdensity lipoprotein cholesterol and the risk of cancer in randomized controlled trial of lipid-altering therapy. J Am Coll Cardiol. 2010; 55(25):2846-2854.

15. Scribano D, Baroni S, Pagano L, Zuppi C, Leone G, Giardina B. Return to normal values of lipid pattern after effective chemotherapy in acute lymphoblastic leukemia. Haematologica. 1996;81(4):343-345.

16. Kucharska-Newton AM, Rosamond WD, Schroeder JC, et al. HDLcholesterol and the incidence of lung cancer in the Atherosclerosis Risk in Communities (ARIC) study. Lung Cancer. 2008;61(3):292-300.

17. Warnick GR, Mayfield C, Benderson J, Chen JS, Albers JJ. HDL cholesterol quantitation by phosphotungstate- $\mathrm{Mg}^{2+}$ and by dextran sulfate- $\mathrm{Mn}^{2+}$-polyethylene glycol precipitation, both with enzymatic cholesterol assay compared with lipid research method. Am J Clin Pathol. 1982;78(5):718-723.

18. Cheng T, Dai X, Zhou DL, Lv Y, Miao LY. Correlation of apolipoprotein A-I kinetics with survival and response to first-line platinum-based chemotherapy in advanced non-small cell lung cancer. Med Oncol. 2015;32(1):407.

19. Pao W, Miller V, Zakowski M, et al. EGF receptor gene mutations are common in lung cancers from "never smokers" and are associated with sensitivity of tumors to gefitinib and erlotinib. Proc Natl Acad Sci U SA. 2004;101(36):13306-13311.

20. Sequist LV, Joshi VA, Janne PA, et al. Response to treatment and survival of patients with non-small cell lung cancer undergoing somatic EGFR mutation testing. Oncologist. 2007;12(1):90-98.

21. Hsiao SH, Liu HE, Lee HL, et al. Distinct clinical outcomes of non-small cell lung cancer patients with epidermal growth factor receptor (EGFR) mutations treated with EGFR tyrosine kinase inhibitors: non-responders versus responders. PLoS One. 2013;8(12):e83266.

22. Tsai CM, Chen JT, Chiu CH, Lai CL, Hsiao SY, Chang KT. Combined epidermal growth factor receptor (EGFR)-tyrosine kinase inhibitor and chemotherapy in non-small-cell lung cancer: chemo-refractoriness of cells harboring sensitizing-EGFR mutations in the presence of gefitinib. Lung Cancer. 2013;82(2):305-312.

23. Simons K, Ikonen E. How cells handle cholesterol. Science. 2000; 290(5497):1721-1726.

24. Chi PD, Liu W, Chen H, et al. High-density lipoprotein cholesterol is a favorable prognostic factor and negatively correlated with C-reactive protein level in non-small cell lung carcinoma. PLoS One. 2014;9(3):e91080.

25. Chen X, Resh MD. Cholesterol depletion from the plasma membrane triggers ligand-independent activation of the epidermal growth factor receptor. J Biol Chem. 2002;277(51):49631-49637.

26. Adam RM, Mukhopadhyay NK, Kim J, et al. Cholesterol sensitivity of endogenous and myristoylated Akt. Cancer Res. 2007;67(13): $6238-6246$. 
27. Elmore S. Apoptosis: a review of programmed cell death. Toxicol Pathol. 2007;35(4):495-516.

28. Irwin ME, Mueller KL, Bohin N, Ge Y, Boerner JL. Lipid raft localization of EGFR alters the response of cancer cells to the EGFR tyrosine kinase inhibitor gefitinib. J Cell Physiol. 2011;226(9):2316-2328.

29. Shields PG. Molecular epidemiology of smoking and lung cancer. Oncogene. 2002;21(45):6870-6876.

30. Siemianowicz K, Gminski J, Stajszczyk M, et al. Serum HDL cholesterol concentration in patients with squamous cell and small cell lung cancer. Int J Mol Med. 2000;6(3):307-311.

31. Umeki S. Decreases in serum cholesterol levels in advanced lung cancer. Respiration. 1993;60(3):178-181.

32. Anchisi C, Batetta B, Sanna F, Fadda AM, Maccioni AM, Dessi S. HDL subfractions as altered in cancer patients. J Pharm Biomed Anal. 1995; 13(1):65-71.
33. Barter P, Gotto AM, LaRosa JC, et al. HDL cholesterol, very low levels of LDL cholesterol, and cardiovascular events. $N$ Engl J Med. 2007; 357(13):1301-1310.

34. Kuvin JT, Karas RH. The effects of LDL reduction and HDL augmentation on physiologic and inflammatory markers. Curr Opin Cardiol. 2003;18(4):295-300.

35. Negre-Salvayre A, Dousset N, Ferretti G, Bacchetti T, Curatola G, Salvayre R. Antioxidant and cytoprotective properties of high-density lipoproteins in vascular cells. Free Radic Biol Med. 2006;41(7): $1031-1040$
OncoTargets and Therapy

\section{Publish your work in this journal}

OncoTargets and Therapy is an international, peer-reviewed, open access journal focusing on the pathological basis of all cancers, potential targets for therapy and treatment protocols employed to improve the management of cancer patients. The journal also focuses on the impact of management programs and new therapeutic agents and protocols on

\section{Dovepress}

patient perspectives such as quality of life, adherence and satisfaction The manuscript management system is completely online and includes a very quick and fair peer-review system, which is all easy to use. Visit http://www.dovepress.com/testimonials.php to read real quotes from published authors. 